\title{
A QSPR study of hydrophobicity of phenols and 2-(aryloxy- $\alpha$-acetyl)-phenoxathiin derivatives using the topological index ZEP
}

\section{ZOIŢA-MĂRIOARA BERINDE}

\section{ABSTRACT.}

The molecular hydrophobicity $\left(R_{M O}\right)$ of several newly synthesized phenoxathiin derivatives and of phenols with congeneric structures have been recently correlated with some simple physico-chemical calculated parameters of compounds: the water solubility (log $\left.S_{w}\right)$; the partition coefficient $(\log P)$; the Gibbs energy of formation $\left(\Delta G_{f}\right)$, and the aromaticity index (HOMA) [Beteringhe, A., Radutiu, A. C., Constantinescu, T., Patron, L. and Balaban, A. T., Quantitative Structure-Property Relationship (QSPR) study of the hydrophobicity of phenols and 2-(aryloxy- $\alpha$-acetyl)phenoxathiin derivatives, Rev. Chim. (Bucureşti), 59 (2008), No. 11, 1175-1179]. The best correlation was found as a biparametric regression equation in terms of $\log S_{w}$ and HOMA, which cannot be improved by adding one or two of the parameters aforementioned.

In the present work we describee the weighted electronic distance based topological index (ZEP) and then use it for QSPR studies of $R_{M O}$ in combination with $\log S_{w}, \log P, \Delta G_{f}$ and HOMA. Most of the three parameter QSPR correlations of $R_{M O}$ are significantly improved by involving the theoretical parameter ZEP.

\section{REFERENCES}

[1] Balaban, A. T., Applications of graph theory in chemistry, J. Chem. Inf. Comput. Sci., 25 (1985), 334-343

[2] Barysz, M., Jashari, G., Lall, R. S., Srivastaya, V. K. and Trinajstić, N., On the Distance Matrix of Molecules Containing Heteroatoms, in Chemical Applications of Graph Theory and Topology, King, R. B. (Ed), Elsevier, Amsterdam, 1983, 222-230

[3] Berinde, Z., Applications of Molecular Topology in the Study of Physico-chemical Properties of Organic Compounds (in Romanian), Cub Press 22, Baia Mare, 2001

[4] Berinde, Z., Consideraţii privind modelarea matricială a compuşilor halogenaţi, Rev. Chim. (Bucureşti), 52 (2001), No. 12, 788-792

[5] Berinde, Z., Un nou indice topologic de tip Randić, Rev. Chim. (Bucureşti), 53 (2002), No. 1, 812-816

[6] Berinde, Z. and Drinkal, C., On a local invariant for modeling molecular double bonds graphs, Chem. Bull. "Politehnica" Univ. (Timişoara), 49 (63) (2004), No. 1-2, 8-10

[7] Berinde, Z. and Drinkal, C., Molecular modelling of molar refraction for alkanes, Chem. Bull. "Politehnica" Univ. (Timişoara), 49 (63) (2004), No. $1-2,4-7$

[8] Berinde, Z., Vertex- and edge-weighted molecular graphs for amines, Rev. Roum. Chim., 51 (2006), No. 11, $1131-1135$

[9] Berinde, Z., QSPR modelling of molar volume of alkanes using the ZEP topological index, Creat. Math. Inf. 17 (2008), No. 3, 308-312

[10] Berinde, Z., Matrix mathematical models used in the representation of molecular structures, Sc. Stud. Res. Ser. Math. Inf., 19 (2009), No. 2, 59-70

[11] Beteringhe, A., Radutiu, A. C., Constantinescu, T., Patron, L. and Balaban, A. T., Quantitative Structure-Property Relationship (QSPR) study of the hydrophobicity of phenols and 2-(aryloxy- $\alpha$-acetyl)-phenoxathiin derivatives, Rev. Chim. (Bucurec sti) , 59 (2008), No. 11, 1175-1179

[12] Diudea, M. and Ivanciuc, O., Molecular Topology (in Romanian), Comprex, Cluj-Napoca, 1995

[13] Estrada, E., Edge adjacency relationships in molecular graphs containing heteroatoms: A novel topological index related to molar volume, J. Chem. Inf. Comput. Sci., 35 (1995), 701-707

[14] Randić, M., Novel Graph Theoretical Approach to Heteroatoms in Quantitative Structure-Activity Relationships, Chemometrics Intel. Lab. Syst., 10 (1991), 213-227

[15] Randić, M., New J. Chem., 15, 1991, p. 517; J. Chem. Inf. Comput. Sci., 31, 1991, p. 311

[16] Trinajstić, N., Chemical Graph Theory , 2nd revised edition, vol. II, CRC Press, Boca Raton, Florida, 1992

[17] Wiener, H., Structural determination of paraffins boiling points, J. Amer. Chem. Soc. 69 (1947), 17-20

[18] Dragon Evaluation for Windows (Software for Molecular Descriptors calculations), Version 5.4, 2006, Talete srl, http://www.talete.mi.it/

[19] Molecular Modeling Pro, Version 6.10 trial, www.norgwyn.com/

\author{
DEPARTMENT OF CHEMISTRY AND Biology \\ NORTH University CENTER AT BAIA MARE \\ TECHNICAL UNIVERSiTy OF CLUj-NAPOCA \\ VictORIEI 76, 430122 BAIA MARE, ROMANIA \\ E-mail address: zoitaberinde@ubm.ro \\ E-mail address: zoita_berinde@yahoo.com
}

